\title{
Zeolite-SPION Nanocomposite for Ammonium and Heavy Metals Removal from Wastewater
}

\author{
Helton P. Nogueira, ${ }^{\circledR *, a}$ Sergio H. Toma, ${ }^{a}$ Alceu T. Silveira Jr. ${ }^{a}$ and Koiti Araki ${ }^{\circledR *, a}$ \\ ${ }^{a}$ Departamento de Química Fundamental, Instituto de Química, Universidade de São Paulo, \\ 05508-000 São Paulo-SP, Brazil
}

\begin{abstract}
Minimizing the emission of industrial effluents and realizing the recovery/extraction of key elements such as the rare earths from low concentration solutions, or during water decontamination processes, are some of the biggest challenges of modern society. Accordingly, the preparation and characterization of a low cost recyclable and reusable superparamagnetic iron oxide nanoparticles (SPION)/zeolite nanocomposite (Zmag) is described, and the possibility of their use for removal of heavy metals and ammonium/ammonia is discussed, generating water whose quality is in compliance with the more strict modern environmental laws. Such materials are suitable for realization of a more efficient dispersion method for adsorption in combination with magnetically aided concentration/separation processes for removal of contaminants. In fact, Zmag was shown to efficiently remove $\mathrm{Pb}^{\mathrm{II}}$ and $\mathrm{Hg}^{\mathrm{II}}$, as well as $\mathrm{NH}_{4}{ }^{+}$from water, generating effluents that can be directly disposed in water bodies according to the current environmental law requirements, as stated by EPA (North America Environmental Protection Agency). That nanocomposite material has a competitive production cost and allowed a cutback in the nitrogen $\left(\mathrm{NH}_{3}\right)$ content from $300 \mathrm{mg} \mathrm{L}^{-1}$ (diluted slurry source) to less than $36 \mathrm{mg} \mathrm{L}^{-1}$. Furthermore, Zmag demonstrated high capacity to concentrate and recover in a cyclic way $\mathrm{La}^{\mathrm{III}}$.
\end{abstract}

Keywords: zeolite, magnetic solid phase extraction (SPE), heavy metals, ammonium, water decontamination, environmental remediation

\section{Introduction}

The continuously increasing concentration of contaminants and demand of water resources since the industrial revolution in the eighteenth century to the present days, have led to the generation of many pollutants with potential to impair the environment and the public health. Among the most prevalent contaminants are the elements with broad toxicity and carcinogenicity, ${ }^{1}$ the most dangerous pollutants to living organisms in general. Such species known as "heavy metals" and "potentially toxic elements" are elementary species that have an atomic density larger than $5 \mathrm{~g} \mathrm{~mL}^{-1}$, generally transition metals such as cadmium and mercury, and representative elements such as thallium and lead. ${ }^{2,3}$

Such anthropogenic contaminants come from various sources especially from industrial, including mining, and agricultural activities. In contrast with organic contaminants, they are not biodegradable and tend to accumulate in living organisms ${ }^{4}$ since have quite a high

*e-mail: helton.nogueira@usp.br; koiaraki@iq.usp.br affinity for sulfur-donor ligands and strongly coordinate to biomolecules, for example, inactivating certain essential enzymes, thus inducing harmful effects to the organism, as widely reported in the literature. ${ }^{5}$ Proteins carboxylate and amino groups also can contribute in that process since tend to increase the affinity while complementing the coordination sphere of those metal complex species.

One of the most well-known contaminants is mercury, which has been used since the prehistoric era as cinnabar red paint $(\mathrm{HgS})$, and until more recently in medicine as treatment for syphilis, as well as amalgam for dental repair fillings ${ }^{6}$ that still is a relevant source of contamination by elemental mercury nowadays. In fact, the population continues to be exposed to this element through food, especially fish, an important exposure route to methyl mercury. ${ }^{7}$ Furthermore, several experimental studies have shown that mercury vapor is released from amalgam used in dental restorations, whose rate may increase during chewing. ${ }^{8}$ Occupationally, mining is one of the activities that most exposes workers to mercury, compromising their health and also the water bodies nearby mines. ${ }^{9}$ 
Acute exposure to mercury can cause lung damage whereas chronic poisoning is characterized by neurological and psychological symptoms such as tremors, personality changes, restlessness, anxiety, sleep disorders and depression. Fortunately, those symptoms tend to be reversed upon cessation of exposure since the blood-brain barrier protects the central nervous system against inorganic mercury. However, "organic mercury" species, especially methyl mercury, can pass through the barrier compromising the brain, and has a latency period of more than a month. In addition, high doses can lead to death usually 2 to 4 weeks after the onset of symptoms. ${ }^{10}$

Among the potentially toxic metals, there is a high concern on lead because of its widespread use and exposure of the population in general to that contaminant through the air and foodstocks. During the last century, emissions into the air coming from cars using gasoline additivated with tetraethyl lead (an anti-knocking agent) increased dramatically the environmental pollution and exposure to this element. ${ }^{11,12}$

Occupational exposure to inorganic lead occurs in mines and foundries, as well as welding of lead-painted metals, and in some battery plants, but the improper disposal of effluents in water bodies is a major issue responsible for a considerable increase in the population exposure. As the maximum limit of lead disposal allowed by law is $0.5 \mathrm{mg} \mathrm{L}^{-1}$ (Conselho Nacional do Meio Ambiente, CONAMA, Resolution No. 430) ${ }^{13}$ its proper treatment is still a challenge. Acute lead poisoning can cause headaches, irritability, pain and various nervous system related symptoms. Lead encephalopathy is characterized by insomnia and restlessness, that can evolve to acute psychosis, confusion and reduced awareness in severe cases. Children may be affected by behavioral disturbance, as well as difficulty in learning and focusing. In addition, IARC (International Agency for Research on Cancer) has classified lead as a "possible human carcinogen" (especially lung cancer, stomach cancer and gliomas) based on data from animal and human studies, but the evidences are been yet considered weak. ${ }^{14}$

Highly persistent organic and inorganic pollutants with strong tendency to accumulate in living organisms, such as the heavy metals mentioned above, are concentrated in the various trophic levels, severely impairing the whole ecosystem..$^{15}$ They represent ecotoxicological hazards of worldwide concern that threatens especially the higher animals, thus clearly requiring urgent and more effective monitoring, treatment and control. ${ }^{16}$

Typical waste treatment processes include filtration, osmosis, precipitation, oxidation or reduction, ion exchange and adsorption processes. Despite the advantages and disadvantages of each method, the porous, complexing and/ or adsorbent materials offer efficient alternatives for water treatment, being one of the few alternatives to achieve the low contaminant concentration limits imposed by current legislation. ${ }^{17}$

Ammonia is a fundamental raw material of fertilizers ${ }^{18}$ and the main responsible for the remarkable increase in agricultural productivity in the last century. But, also is a widespread contaminant whose industrial discharge must comply with Resolutions No. 357 and 430 of CONAMA, ${ }^{13,19}$ the institution responsible for monitoring the water quality standards in Brazil and that set a maximum limit of $20 \mathrm{mg} \mathrm{L}^{-1} \mathrm{~N} / \mathrm{NH}_{3}$ in treated wastewater. In fact, ammonia is very harmful to fish and many aquatic species do not withstand concentrations above $5 \mathrm{mg} \mathrm{L}^{-1}$, but some species are much more sensitive and concentrations should be kept below $0.01 \mathrm{mg} \mathrm{L}^{-1}$ to assure optimal conditions. ${ }^{20} \mathrm{In}$ addition, ammonia is a strong eutrophicating agent causing abnormal proliferation of algae and aquatic plants, and consequently higher biological oxygen demand (BOD) during their decomposition process. ${ }^{21}$ However, many companies fail to meet the standards required by legislation due to the inefficient treatment processes being used.

Adsorbents also can be used for concentration and removal of this valuable compound, as expected for key materials for concentration of contaminants in water. However, their application for treatment of large volumes is being hindered by drawbacks such as the generally short interaction times (and thus adsorption efficiency) and pressure drop when applied as adsorbent beds. In this work, zeolite grains were decorated with superparamagnetic iron oxide nanoparticles (SPION) in order to impart magnetic properties to them, facilitating their recovery and recycling from larger volumes by simple magnetically aided precipitation, thus increasing the technological competitiveness for removal of contaminants such as heavy metal ions and ammonia from water.

\section{Experimental}

\section{Preparation of the magnetic zeolite (Zmag)}

Superparamagnetic nanoparticles were prepared by a thermal decomposition method, ${ }^{22}$ carefully dispersed in water and bound onto the surface of zeolite $\mathrm{Y}$ (Sigma-Aldrich, USA) granules, generating a composite material denominated Zmag upon solvent removal in a flash evaporator. The solid was washed with water and subsequently with acetone, generating a powder material that was dried in an oven at $120^{\circ} \mathrm{C}$, and stored in a desiccator for use. The production cost estimated 
based on zeolite Y purchased in quantity was less than US\$ 10.00 per kilogram. Further manufacturing details can be found in recently filed patent applications..$^{23,24}$

\section{Characterization of Zmag}

Scanning electron microscopy images were registered in a Jeol JSM-7401F field emission microscope at acceleration potential from $2 \mathrm{kV}$ up to $20 \mathrm{kV}$. Samples were prepared by depositing small amounts of the solid material on a silicon substrate, which was fixed onto a brass stub with a carbon conductive tape or a copper conductive adhesive.

The magnetic hysteresis curves were obtained measuring the magnetic moments in the $10^{-3}$ to $10^{3} \mathrm{emu} \mathrm{g}^{-1}$ range, in the Laboratory of Magnetic Materials (LMM), Department of Materials Physics, of Institute of Physics of University of São Paulo. The measurements were carried out in an EG\&G Princeton Applied Research Corporation, Model 4500 vibrating sample magnetometer (VSM), coupled with a Walker Scientific model HR8 electromagnet with nominal magnetic field varying from zero up to 20 kOe (2 T), and a Lake Shore model 450 Gaussmeter. The routine protocol consisted in sweeping the magnetic field while measuring the corresponding magnetization of the sample, from $+20 \mathrm{kOe}$ down to $-20 \mathrm{kOe}$ and reversing the scan back to $20 \mathrm{kOe}$, closing a complete cycle.

Porosity and surface area measurements were performed on a Quantachrome NOVA 4000 nitrogen flow adsorption analyzer, averaging out 34 measurements for each nitrogen adsorption datum of the isotherm. Data acquisition were performed after degassing the samples for $3 \mathrm{~h}$ at a temperature of $200{ }^{\circ} \mathrm{C}$, and the Brunauer-Emmett-Teller (BET) method was used for determination of the surface area.

$\mathrm{X}$-ray fluorescence spectra were obtained by total reflection X-ray fluorescence (TXRF) spectroscopy at room temperature, using a Bruker Picofox S2 spectrometer equipped with a molybdenum source (50 $\mathrm{kV}$ voltage) and a Si(Li) XFlash ${ }^{\circledR}$ detector refrigerated by Peltier effect. The analyzes were performed using Ga and Ti internal standards, and samples prepared as polyvinyl alcohol (PVA) films by drop casting on suitable ultrapure quartz substrates. The exact amount of Fe equivalent to a magnetite content of $10 \mathrm{wt} . \%$ was determined after digestion of Zmag with concentrated hydrochloric acid (Synth, Brazil), using gallium and titanium internal standards (Sigma-Aldrich, USA).

\section{Adsorption isotherms}

Measurements of the ammonium removal capacity were performed by treating $20 \mathrm{~mL}$ of a $\mathrm{pH} 5$ ammonium chloride solution $\left(\mathrm{NH}_{4}{ }^{+}\right.$concentration ranging from 8 to $\left.440 \mathrm{mg} \mathrm{L}^{-1}\right)$ with $0.5 \mathrm{wt} . \%$ of Zmag, after contact for $60 \mathrm{~s}$ under agitation in a Corning model LSE6776 vortex. Then, the solid was magnetically separated and the supernatant treated with $10 \mu \mathrm{L}$ of concentrated sulfuric acid for sample preservation purpose, and determination of the $\mathrm{NH}_{4}{ }^{+}$concentration by potentiometry using an ion selective electrode (ISE, Thermo Scientific Orion Star A111 Benchtop pH/ISE/mV/ Temperature Meter).

The metal cation removal capacity of Zmag was measured in a similar way as above for ammonium, by treating $10 \mathrm{~mL}$ of each one of the metal ion solution with 0.5 wt. \% of Zmag, after $60 \mathrm{~s}$ in a Corning model LSE6776 vortex. Then, the adsorbent was magnetically separated and the supernatant analyzed by TXRF using the Bruker Picofox S2 spectrometer. The standard curves were prepared incorporating the metal ions in the PVA films in the following ranges: (i) $\mathrm{Pb}^{\mathrm{II}}$ from 2 to $8000 \mathrm{mg} \mathrm{L}^{-1}$, (ii) $\mathrm{Hg}^{\mathrm{II}}$ from 2.5 to $260 \mathrm{mg} \mathrm{L}^{-1}$, and (iii) $\mathrm{La}^{\mathrm{III}}$ from 2 to $2500 \mathrm{mg} \mathrm{L}^{-1}$.

\section{Results and Discussion}

\section{Materials}

The morphology of the magnetic nanocomposites was evaluated by scanning electron microscopy (FEG-SEM) in order to verify the dispersion of SPIONs on the zeolite grain surface.

Pure zeolite was shown to be constituted by about $1 \mu \mathrm{m}$ large granules with perfectly smooth surface but exhibiting signs characteristic of fragile fractures, as expected for a mechanically milled hard material, as shown in Figure S1 (Supplementary Information (SI) section). The SEM image after incorporation of $10 \mathrm{wt} . \%$ of SPION indicated the presence of small spherical features uniformly distributed on the surface (Figure 1a), thus confirming their attachment and formation of the Zmag nanocomposite.

The formation of the zeolite-based nanocomposite is also confirmed by VSM measurements (Figure 1b) indicating a magnetization of $3.7 \mathrm{emu} \mathrm{g}^{-1}$ at magnetic fields above $10 \mathrm{kOe}$, in the superparamagnetic regime. That value is in good agreement with the expected theoretical saturation magnetization of $4 \mathrm{emu} \mathrm{g}^{-1}$ considering the relative amounts of SPION and zeolite used in the synthesis, thus indicating that almost all SPION was incorporated into the zeolite. That result was confirmed by TXRF spectroscopy analysis, when the exact amount of $\mathrm{Fe}$ equivalent to a magnetite content of $10 \mathrm{wt} . \%$ was determined after digestion of Zmag (as informed in the Experimental section), as shown in Figure S2 (SI section). 

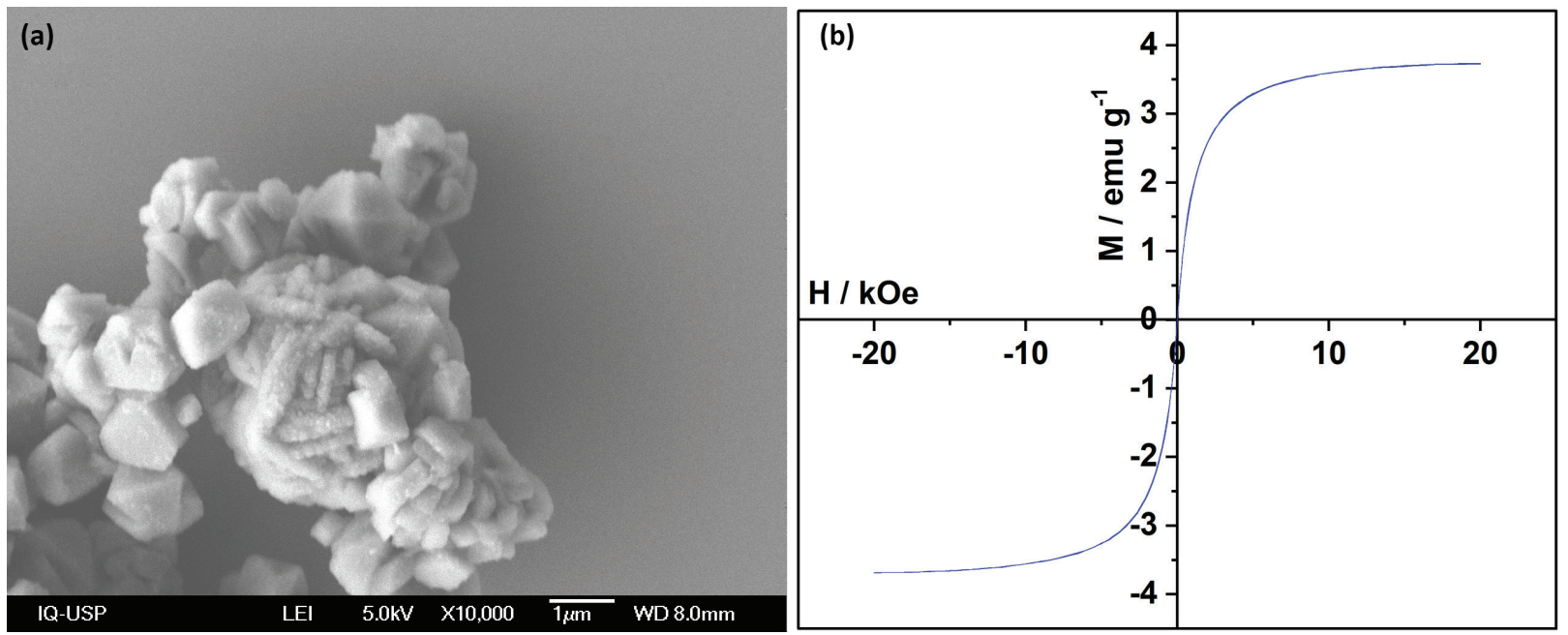

Figure 1. (a) FEG-SEM images of Zmag nanocomposite (magnification of 10,000x) obtained by attachment of SPIONs onto zeolite grain surface, and (b) respective magnetization curve in the -20 to $+20 \mathrm{kOe}$ range determined by VSM technique.

\section{Porosity and surface area}

The surface area of the pure zeolite $\mathrm{Y}$ and after incorporation of SPIONs were determined by registering the corresponding nitrogen adsorption isotherms and performing data analysis by BET. A large decrease in surface area was expected upon incorporation of nanoparticles into porous adsorbent materials since they tend to enter into clogging pores and limiting the access to the adsorption sites, thus reducing their adsorption capacity. However, the reduction in surface area (less than 16\%), pore size (less than 8.7\%) and volume was much less than expected (Table 1) indicating the preferential binding of SPIONs onto the surface. In fact, this is a fundamental requirement to get composite materials with as high as possible adsorption capacity and magnetic properties to allow fast magnetically aided precipitation and separation from water.

The adsorption/desorption isotherm exhibited a typical type II profile (Figure 2), with an initially rapid adsorption corresponding to the formation of a monolayer on the surface of the material (a type I isotherm), followed by a new stage at much higher pressures attributed to the onset of multilayers of adsorbed molecules, as expected for nitrogen condensation. Type II isotherms are typical of microporous systems where both, the occupation of surface sites and the filling of capillary micropores are observed. ${ }^{16}$ The amount of nitrogen molecules adsorbed in the first step was much larger for Zmag than zeolite Y, and almost no hysteresis for desorption was observed, the capillary filling being the dominant process in the second stage of the isotherm. In contrast, zeolite $\mathrm{Y}$ exhibited rapid saturation of the surface sites and a significant hysteresis for desorption can be noticed.

\section{Adsorption capacity}

The adsorption parameters in aqueous solution were evaluated by nonlinear fitting of the adsorption/desorption isothermal curves based on Langmuir and LangmuirFreundlich models, as described by equations 1 and 2 , respectively. ${ }^{25,26}$

$\mathrm{q}_{\mathrm{e}}=\frac{\mathrm{KbC}_{\mathrm{eq}}}{1+\mathrm{KC}_{\mathrm{eq}}}$

$\mathrm{q}_{\mathrm{e}}=\frac{\mathrm{b}\left(\mathrm{C}_{\mathrm{eq}}\right)^{\mathrm{nLF}}}{\mathrm{K}_{\mathrm{dLF}}+\left(\mathrm{C}_{\mathrm{eq}}\right)^{\mathrm{nLF}}}$

where $\mathrm{q}_{\mathrm{e}}$ is the amount of adsorbate adsorbed on the material under a given experimental condition $\left(\mathrm{mg} \mathrm{g}^{-1}\right)$; $\mathrm{K}$ is a dimensionless thermodynamic constant whose value is proportional to the adsorbent/adsorbate interaction energy; $\mathrm{b}$ is the maximum capacity of the adsorbent under a given experimental condition $\left(\mathrm{mg} \mathrm{g}^{-1}\right) ; \mathrm{C}_{\mathrm{eq}}$ is the concentration

Table 1. Average surface area, volume and pore size of zeolite Y and Zmag nanocomposite measured by BET method

\begin{tabular}{lccc}
\hline Adsorbent material & Surface area $/\left(\mathrm{m}^{2} \mathrm{~g}^{-1}\right)$ & Pore volume $/\left(\mathrm{cm}^{3} \mathrm{~g}^{-1}\right)$ & Pore size $/ \AA$ \\
\hline Zeolite Y & 721 & 0.4 & 23 \\
Zmag & 604 & 0.3 & 21 \\
\hline
\end{tabular}

Zmag: superparamagnetic iron oxide nanoparticles (SPION)/zeolite nanocomposite. 

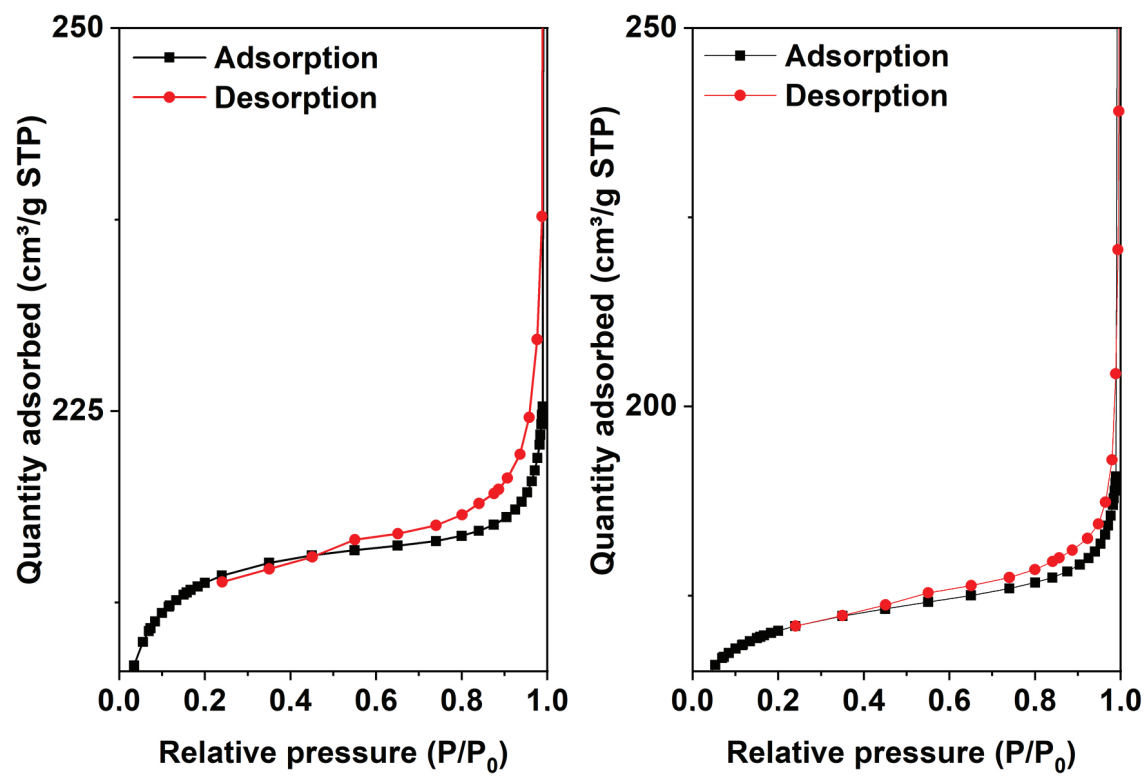

Figure 2. $\mathrm{N}_{2}$ adsorption/desorption isotherms for pure zeolite $\mathrm{Y}$ (left) and Zmag nanocomposite (right), at $77 \mathrm{~K}$.

of adsorbate at equilibrium in solution $\left(\mathrm{mg} \mathrm{L}^{-1}\right)$ per gram of adsorbent; $\mathrm{n}$ is a dimensionless constant inherent to a given adsorbate/adsorbent at a given temperature; $\mathrm{nLF}$ is a dimensionless parameter proportional to the adsorbateadsorbent affinity; $\mathrm{K}_{\mathrm{dLF}}$ is a dimensionless apparent thermodynamic association constant.

The first one is the most simple model and considers the presence of equivalent non-interacting adsorption sites, leading to the formation of a monolayer of adsorbate on the surface..$^{27}$ The Freundlich's model, in contrast, considers the possibility of interactions between neighboring adsorption sites, as well as adsorbate/adsorbate interactions, leading to deposition of multiple adsorbate layers. ${ }^{28}$ Finally, the Langmuir-Freundlich model considers the concomitant presence of both types of adsorption sites.

\section{Removal of ammonia/ammonium}

The adsorption isotherm data (filled squares) shown in Figure 3 were fitted (equations 1 and 2) resulting in an ammonium saturation concentration $\mathrm{b}=31 \mathrm{mg} \mathrm{g}^{-1}$ $(\mathrm{K}=0.05)$ and $\mathrm{b}=37.48 \mathrm{mg} \mathrm{g}^{-1}\left(\mathrm{~K}_{\mathrm{dLF}}=0.08\right.$ and $\left.\mathrm{n}=0.7\right)$, respectively according to the Langmuir and LangmuirFreundlich model. The last one gives a much better fitting, since considers the possible hydrogen bonding interactions of the first $\mathrm{NH}_{4}{ }^{+}$ions layer with a second $\mathrm{NH}_{3}$ layer generating a pseudo double-layer. It is also interesting to point out that the saturation concentration values obtained according to both models are higher than that of many pure natural zeolites. For example, Wang and Peng ${ }^{29}$ reported in a review article that zeolites have ammonium adsorption capacity in the 2.7 to $30.6 \mathrm{mg} \mathrm{g}^{-1}$ range. Probably, this is due to the fact that the commercial zeolite we used for preparation of the composite has only $\mathrm{Na}^{+}$as counterion neutralizing the negative charges resulting from the isomorphic substitution of $\mathrm{Si}^{4+}$ by $\mathrm{Al}^{3+}$ ions,${ }^{30}$ whilst natural zeolites can incorporate other cations with much larger affinity for the adsorption sites than $\mathrm{Na}^{+}$thus attenuating their efficiency as cation exchangers.

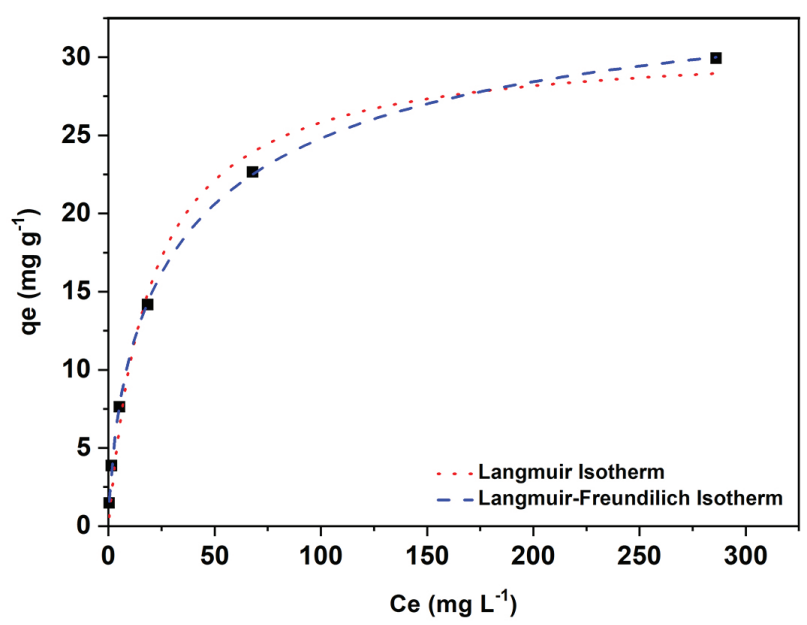

Figure 3. Isothermal adsorption curve of the $\mathrm{NH}_{4}{ }^{+}$cation by $250 \mathrm{mg}$ of $\mathrm{Zmag}$, at $\mathrm{pH}$ 5, and respective fitting curves according to Langmuir and Langmuir-Freundlich models.

The quite high ammonium/ammonia adsorption efficiency of Zmag was confirmed by carrying out tests using $10 \mathrm{wt} . \%$ of the material to treat $\mathrm{pH} 5$ aqueous solution with increasing concentrations of ammonium. No significant amounts could be detected in the solution after treatment of solutions with initial ammonium concentrations below $20 \mathrm{mg} \mathrm{L}^{-1}$ (Figure 4), whereas about 
$8 \%$ remained in solution when the initial concentration was increased to $100 \mathrm{mg} \mathrm{L}^{-1}$.

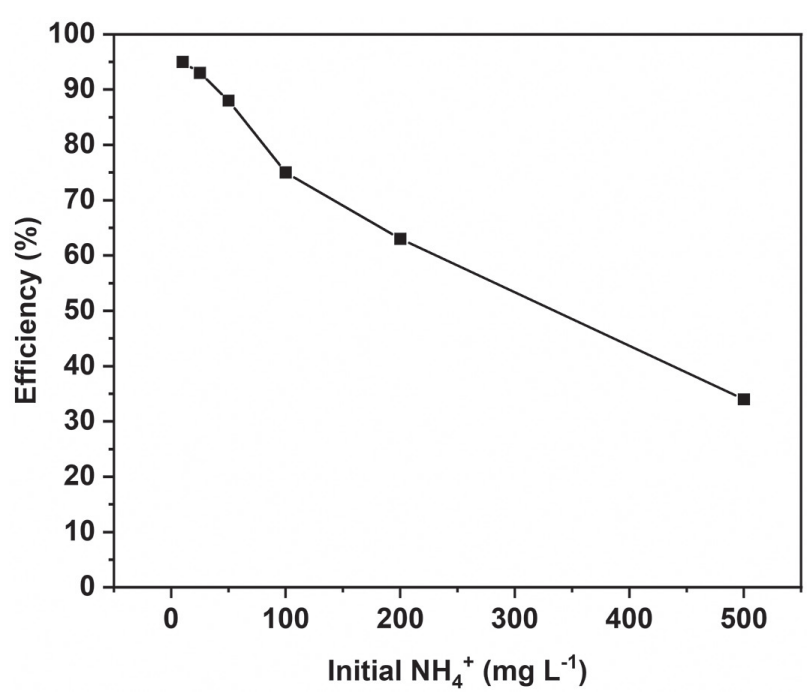

Figure 4. Plot of the percentage of ammonium removed from solution by $10 \mathrm{wt} . \%$ of $\mathrm{Zmag}$ at $\mathrm{pH} 5$ as a function of the initial concentration of ammonium measured by ISE potentiometry, showing the $\mathrm{NH}_{4}{ }^{+}$ion removal capacity of the nanocomposite material.

Considering its potential technological application, the efficiency of the nanocomposite material for extraction of ammonia/ammonium was evaluated using a commercial colorimetric method (Figure S3, SI section). Alfakit ${ }^{\circledR}$ is an environmental analysis kit commonly used to quantify the concentration of ammonia/ammonium present in water samples right in the field. The Zmag nanocomposite $(0.4 \mathrm{~g})$ was added into and stirred with $4 \mathrm{~mL}$ of $100 \mathrm{mg} \mathrm{L}^{-1}$ $\mathrm{NH}_{4}^{+}$solution (initial concentration), giving a supernatant with $0.5-1.0 \mathrm{mg} \mathrm{L}^{-1}$ of $\mathrm{NH}_{4}^{+}$(Figure $\mathrm{S} 3 \mathrm{~g}$ ) after magnetic separation. The recovered solid was subjected to a second ammonium removal process and the supernatant solution subjected to colorimetric assay. This time, the result was consistent with a solution with about 1.0 to $1.5 \mathrm{mg} \mathrm{L}^{-1}$ of $\mathrm{NH}_{4}{ }^{+}$(Figure $\mathrm{S} 3 \mathrm{~h}$ ), indicating that a larger concentration remained in solution, as expected. Finally, the possibility of recovery of the adsorbent material was evaluated by washing the magnetically separated solid with $4 \mathrm{~mL}$ of $100 \mathrm{~g} \mathrm{~L}^{-1} \mathrm{NaCl}$ solution stirring for $1 \mathrm{~min}$, desorbing the ammonium load. The result of the Alfakit ${ }^{\circledR}$ analysis shown in Figure S3i clearly indicates a solution with more than $3.0 \mathrm{mg} \mathrm{L}^{-1}$ of $\mathrm{NH}_{4}^{+}$, the recommended limit of that colorimetric method, demonstrating that Zmag can be easily recycled by washing with a $\mathrm{NaCl}$ solution.

In addition, a real sample of an industrial wastewater, a manure sample with an initial concentration of $5430 \mathrm{mg} \mathrm{L}^{-1}$ of ammonia was treated with the adsorbent composite to simulate a real application condition. For this purpose, the sample was diluted with deionized water to give $100 \mathrm{~mL}$ of a $543 \mathrm{mg} \mathrm{L}^{-1}$ sample. An aliquot of $10 \mathrm{~mL}$ was treated with $500 \mathrm{mg}$ of Zmag under stirring for $60 \mathrm{~s}$. After magnetic separation, there was a significant reduction in the turbidity of the sample, indicating concomitant adsorption of solid materials in suspension, as well as a very significant reduction of $87 \%$ in the ammonia content. That is, the concentration of ammonia in solution was reduced from 543 to $70 \mathrm{mg} \mathrm{L}^{-1}$ demonstrating the high ammonia removal capacity of the magnetic nanocomposite.

\section{Removal of metal ions}

The adsorption isotherms of $\mathrm{Pb}^{\mathrm{II}}, \mathrm{Hg}^{\mathrm{II}}$ and $\mathrm{La}^{\mathrm{III}}$ cations (Figure 5) on Zmag present typical saturation profiles where lead(II) showed the highest saturation concentration of $250 \mathrm{mg} \mathrm{g}^{-1}$ of nanocomposite, followed by lanthanum(III) with $118 \mathrm{mg} \mathrm{g}^{-1}$, and mercury(II) with only $10.4 \mathrm{mg} \mathrm{g}^{-1}$ of Zmag, as shown in Figure 5.

The adsorption isotherms are strongly dependent on the concentration and affinity of the adsorption sites for the metal cations, where the removal capacity of each isolated cation showed a positive correlation with the concentration of those contaminants. The isothermal curves were simulated using the equations 1 and 2, but in contrast to ammonia, the Langmuir model gave better fitting than the LangmuirFreundlich model for the heavy metal ions as expected for the formation of a monolayer of the metal cations on the negatively charged zeolite surface. However, the $\mathrm{pH}$ condition had to be adjusted to maximize the affinity of the adsorbate for the adsorbent $\mathrm{Zmag}$. For example, the $\mathrm{pH}$ was adjusted to 5 for lead(II) to give a saturation concentration of $250 \mathrm{mg} \mathrm{g}^{-1}$. In contrast, the mercury(II) solution had to be conditioned to $\mathrm{pH} 8$ to enhance the saturation concentration to $12 \mathrm{mg} \mathrm{g}^{-1} \mathrm{Zmag}$. This value is consistent with the known low capability of zeolite $Y$ to remove mercury cations from aqueous media, as pointed out by Zamzow et al. ${ }^{31}$ However, our result is significantly much larger than the adsorption capacity of $1 \mathrm{mg} \mathrm{g}^{-1}$ of zeolite $\mathrm{Y}$ reported by Murthy et al., ${ }^{32}$ Attari et $a l .{ }^{33}$ and Czarna et al. ${ }^{34}$ even considering the structural and compositional difference of the zeolites. Zmag also outperformed the adsorption capacity of $\mathrm{Pb}^{\text {II }}$ by clinoptilolite zeolite $\left(122.4 \mathrm{mg} \mathrm{g}^{-1}\right)$ as reported by Günay et al., ${ }^{12}$ clearly demonstrating the relevance of controlled attachment of SPIONs onto the grain surface without blocking the zeolite pores as a suitable strategy for preparation of superparamagnetic adsorbent nanocomposites.

The excellent adsorption properties towards heavy metal cations and ammonia as demonstrated by the enhanced recovery capability of Zmag motivated us testing it for the recovery of valuable elements, more specifically 

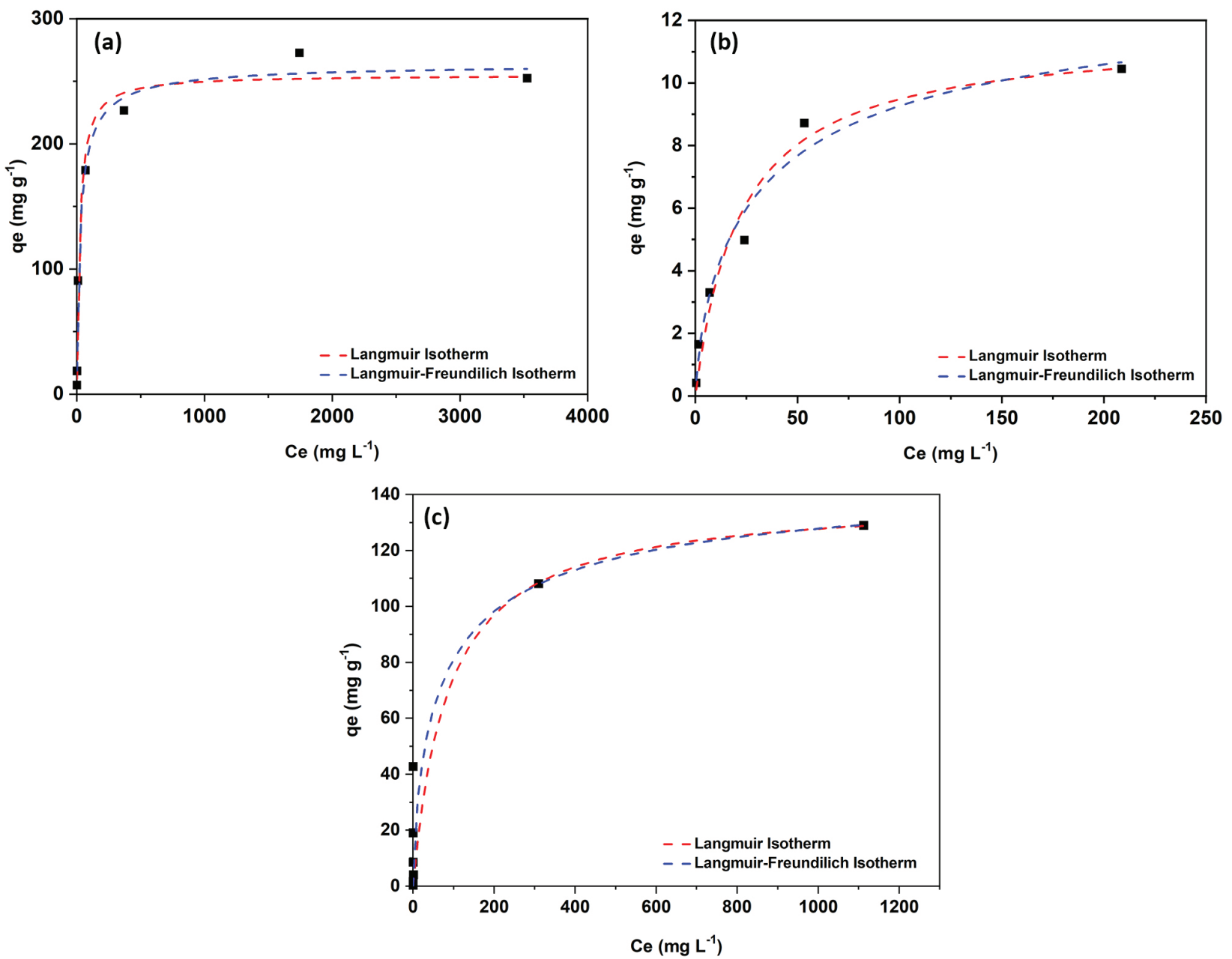

Figure 5. Adsorption isotherms of (a) $\mathrm{pH} 5 \mathrm{~Pb}^{\mathrm{II}}$, (b) $\mathrm{pH} 8 \mathrm{Hg}^{\mathrm{II}}$ and (c) $\mathrm{pH} 5 \mathrm{La}^{\mathrm{III}}$ solutions on $\mathrm{Zmag}$, and respective fitting curves using the Langmuir and Langmuir-Freundlich models.

rare earth ions. In this context, lanthanum(III) salt in aqueous solution was used as a good model considering the known similarity of the physico-chemical properties of rare earth elements. Accordingly, the removal capacity of $\mathrm{Zmag}$ was measured by treating $10 \mathrm{~mL}$ of $\mathrm{La}^{\text {III }}$ aqueous solution with $0.5 \mathrm{wt} . \%$ of $\mathrm{Zmag}$ and interaction time of $60 \mathrm{~s}$ under stirring, in a Corning model LSE6776 vortex. Then, the solid adsorbent was magnetically separated and the $\mathrm{La}^{\mathrm{III}}$ concentration in the supernatant solution analyzed by TXRF. The adsorption isotherm was determined after optimization of the experimental conditions, in other words after adjustment of solution $\mathrm{pH}$ to 4 , when a saturation concentration of $118 \mathrm{mg} \mathrm{g}^{-1} \mathrm{Zmag}$ was achieved. In order to further confirm the suitability of Zmag for concentration and recovery of $\mathrm{La}^{\mathrm{III}}$ from aqueous solution, samples with increasing concentrations were prepared by dilution of a $500 \mathrm{mg} \mathrm{L}^{-1}$ solution. These samples were treated with $1 \mathrm{wt} . \%$ of $\mathrm{Zmag}$, and the rare earth ion recovered/desorbed as previously using $10 \mathrm{~mL}$ of $100 \mathrm{~g} \mathrm{~L}^{-1} \mathrm{NaCl}$ solution by stirring for $60 \mathrm{~s}$ and magnetically assisted separation of solid from solution. The data summarized in Table 2 confirm the complete removal of $\mathrm{La}^{\mathrm{III}}$ from solution by Zmag, except for in the most concentrated one where a low concentration of $1.55 \mathrm{mg} \mathrm{L}^{-1}$ remained in solution. In addition, a good recovery/desorption from the magnetic nanocomposite of 70 to $96 \%$ was observed demonstrating the potentiality of Zmag for recovery of rare earth cations from dilute aqueous solutions.

Table 2. Initial and final equilibrium concentrations of $\mathrm{La}^{\mathrm{III}}$ in aqueous solution measured upon treatment with $1 \mathrm{wt} . \%$ of $\mathrm{Zmag}$, and recovery with a $100 \mathrm{~g} \mathrm{~L}^{-1} \mathrm{NaCl}$ solution

\begin{tabular}{lccc}
\hline $\begin{array}{l}\text { Initial }\left[\mathrm{La}^{\mathrm{II}}\right] / \\
\left(\mathrm{mg} \mathrm{L}^{-1}\right)\end{array}$ & $\begin{array}{c}\text { Final }\left[\mathrm{La}^{\mathrm{II}}\right] / \\
\left(\mathrm{mg} \mathrm{L}^{-1}\right)\end{array}$ & $\begin{array}{c}\text { Recovery / } \\
\left(\mathrm{mg} \mathrm{L}^{-1}\right)\end{array}$ & Recovery /\% \\
\hline 0.86 & 0 & 0.83 & 96 \\
23.62 & 0 & 21.01 & 89 \\
97.07 & 0 & 66.97 & 69 \\
244.98 & 0 & 169.18 & 69 \\
434.69 & 1.55 & 379.02 & 88 \\
\hline
\end{tabular}




\section{Conclusions}

Zmag, a nanocomposite adsorbent that can be easily dispersed and magnetically recovered from aqueous medium, showing high efficiency for removal of $\mathrm{NH}_{4}{ }^{+} / \mathrm{NH}_{3}, \mathrm{Hg}^{\mathrm{II}}, \mathrm{Pb}^{\mathrm{II}}$ and $\mathrm{La}^{\mathrm{III}}$, is described. Such properties were achieved by combining the adsorption capacity of zeolite Y matrix with the magnetic recovery capacity incorporated by attaching SPIONs on the grain surface.

The new nanocomposite material achieved an excellent adsorption performance when compared to similar zeolite materials described in the literature, opening the possibility of remediation/recovering processes based on a more efficient dispersive method, capable of producing final effluents with contaminants in the appropriate concentration range for direct disposal into the environment, while recycling and reusing the material. This can be carried out by simple treatment with a saturated $\mathrm{NaCl}$ solution, making possible carrying out the decontamination concomitantly with recovery of valuable species from water, such as rare earth and ammonium for the fertilizer industry.

\section{Supplementary Information}

Supplementary information about material characterization and lanthanum adsorption assay is available free of charge at http://jbcs.sbq.org.br as PDF file.

\section{Acknowledgments}

H. P. Nogueira thanks Conselho Nacional de Desenvolvimento Científico e Tecnológico for scholarship (CNPq: 141164/2015-8). S. H. Toma thanks CNPq for the Scholarship in Technological Development Productivity (CNPq 305950/2016-9). K. Araki thanks FAPESP (2018/21489-1), Petróleo Brasileiro (Petrobras 0050.0101557.16.9), and CNPq (401581/2016-0 and $303137 / 2016-9$ ) for the financial support.

\section{References}

1. Kim, H. S.; Kim, Y. J.; Seo, Y. R.; J. Cancer Prev. 2015, 20, 232.

2. Rossi, L. M.; Costa, N. J. S.; Silva, F. P.; Wojcieszak, R.; Green Chem. 2014, 16, 2906.

3. Hawkes, S. J.; J. Chem. Educ. 1997, 74, 1374.

4. Fu, F.; Wang, Q.; J. Environ. Manage. 2011, 92, 407.

5. Barceloux, D. G.; J. Toxicol., Clin. Toxicol. 1999, 37, 173.

6. Järup, L.; Br. Med. Bull. 2003, 68, 167.

7. Sunderland, E. M.; Li, M.; Bullard, K.; Environ. Health Perspect. 2018, 126, 017006.
8. Sällsten, G.; Thorén, J.; Barregård, L.; Schütz, A.; Skarping, G.; J. Dent. Res. 1996, 75, 594.

9. Jiang, G.-B.; Shi, J.-B.; Feng, X.-B.; Environ. Sci. Technol. 2006, 40, 3672.

10. Weiss, B.; Clarkson, T. W.; Simon, W.; Environ. Health Perspect. 2002, 110, 851.

11. Bailey, S. E.; Olin, T. J.; Bricka, R. M.; Adrian, D. D.; Water Res. 1999, 33, 2469.

12. Günay, A.; Arslankaya, E.; Tosun, I.; J. Hazard. Mater. 2007, 146, 362.

13. Conselho Nacional do Meio Ambiente (CONAMA); Resolução No. 430 Dispõe sobre As Condições e Padrões de Lançamento de Efluentes, Complementa e Altera a Resolução No. 357, de 17 de março de 2005; Diário Oficial da União (DOU), Brasília, No. 92, de 16/05/2011, p. 89.

14. International Agency for Research on Cancer (IARC); Inorganic and Organic Lead Compounds, vol. 87; World Health Organization International Agency for Research on Cancer: Lyon, 2006.

15. Vendruscolo, F.; Ferreira, G. L. R.; Antoniosi Filho, N. R.; Int. Biodeterior. Biodegrad. 2017, 119, 87.

16. Lu, F.; Astruc, D.; Coord. Chem. Rev. 2018, 356, 147.

17. Ministério do Meio Ambiente; Legislação Ambiental Básica; Ministério do Meio Ambiente e Organização das Nações Unidas para a Educação, a Ciência e a Cultura: Brasília, 2008, available at https://www.mma.gov.br/estruturas/secex_conjur/_ arquivos/108_12082008084425.pdf accessed in May 2020.

18. Qin, M.; Hynes, E. A.; Abu-Reesh, I. M.; He, Z.; J. Cleaner Prod. 2017, 149, 856.

19. Conselho Nacional do Meio Ambiente (CONAMA); Resolução No. 357 Dispõe sobre A Classificação dos Corpos de Água e Diretrizes Ambientais para o seu Enquadramento, bem como Estabelece as Condições e Padrões de Lançamento de Efluentes, e dá outras Providências; Diário Oficial da União (DOU), Brasília, No. 53, de 18/03/2008, p. 58.

20. Rodrigues, J.; Lima, S.; Roberto, F.; Vale, A.; Jackes, F.; Roberto, F.; Lima, S.; Alves, D.; Acta Sci., Biol. Sci. 2013, 35, 475 .

21. Nguyen, M. L.; Tanner, C. C.; N. Z. J. Agric. Res. 1998, 41, 427.

22. Zuin, A.; Cousseau, T.; Sinatora, A.; Toma, S. H.; Araki, K.; Toma, H. E.; Tribol. Int. 2017, 112, 10.

23. Nogueira, H. P.; Silveira Jr., A. T.; Osorio, D. S. G.; Chida, A. Y.; Toma, S. H.; Toma, H. E.; Araki, K.; BR1020170280586, 2017.

24. Nogueira, H. P.; Toma, S. H.; Araki, K.; BR10201902442, 2019.

25. Linhares, L. A.; Egreja Filho, F. B.; de Bellis, V. M.; dos Santos, E. A.; Ianhez, R.; Acta Agron. 2010, 59, 303.

26. Sala, L.; Figueira, F. S.; Cerveira, G. P.; Moraes, C. C.; Kalil, S. J.; Braz. J. Chem. Eng. 2014, 31, 1013.

27. Halsey, G.; J. Chem. Phys. 1948, 16, 931. 
28. Karthikeyan, T.; Rajgopal, S.; Miranda, L. R.; J. Hazard. Mater. 2005, 124, 192.

29. Wang, S.; Peng, Y.; Chem. Eng. J. 2010, 156, 11.

30. Barrer, R. M.; Davies, J. A.; Rees, L. V. C.; J. Inorg. Nucl. Chem. 1969, 31, 2599.

31. Zamzow, M. J.; Eichbaum, B. R.; Sandgren, K. R.; Shanks, D. E.; Sep. Sci. Technol. 1990, 25, 1555.

32. Murthy, Z. V. P.; Parikh, P. A.; Patel, N. B.; J. Dispersion Sci. Technol. 2013, 34, 747.
33. Attari, M.: Mercury Removal from Aqueous Solution Using Natural, Synthetic, and Modified Zeolites; MSc dissertation, University of Western Ontario, Ontario, Canada, 2015, available at https://ir.lib.uwo.ca/etd/3186, accessed in May 2020.

34. Czarna, D.; Baran, P.; Kunecki, P.; Panek, R.; Żmuda, R.; Wdowin, M.; J. Cleaner Prod. 2018, 172, 2636.

Submitted: January 15, 2020 Published online: May 25, 2020 